\title{
Day fines: asymmetric information and the secondary enforcement system
}

\author{
Elena Kantorowicz-Reznichenko ${ }^{1}$ (D) - Maximilian Kerk ${ }^{2,3,4}$
}

Published online: 26 May 2020

(c) The Author(s) 2020

\begin{abstract}
The most common pecuniary sanction, i.e. fixed-fines, places an emphasis on the severity of the crime. This fine has the problem of being either too high for poorer offenders to pay or too low for the richer offenders to be deterred. Day-fines, on the other hand, systematically account for the financial situation of the offender as well as for the severity of his offense. Consequently, it imposes equivalent burden of punishment on offenders who committed similar crimes, regardless of their wealth. However, a problem of asymmetric information is raised. Accurate financial information is essential for the efficiency of day-fines, yet its collection is costly. Day-fines receive increasing attention from policy-makers around the world. Nonetheless, it is under-researched in the law and economics literature. Therefore, this article is the first to formally analyze the problem of asymmetric information in the context of day-fines and to develop an optimal secondary enforcement system that would incentivize criminals to provide accurate information regarding their wealth.
\end{abstract}

Keywords Day-fines $\cdot$ Information $\cdot$ Criminal law $\cdot$ Deterrence $\cdot$ Law and economics

JEL Classification $\mathrm{K} 14 \cdot \mathrm{K} 42$

Elena Kantorowicz-Reznichenko

reznichenko@law.eur.nl

Maximilian Kerk

maximilian.kerk@edle-phd.eu

1 Erasmus University Rotterdam, Rotterdam, The Netherlands

2 Graduate of the European Doctorate in Law and Economics, Erasmus University Rotterdam, Rotterdam, The Netherlands

3 Graduate of the European Doctorate in Law and Economics, University of Bologna, Bologna, Italy

4 Graduate of the European Doctorate in Law and Economics, University of Hamburg, Hamburg, Germany 


\section{Introduction}

It might be said that rich people can put a price on offenses. Most jurisdictions practice a fixed fine ${ }^{1}$ as a pecuniary sanction. Therefore, the wealthier is the person, the more attractive it is for him to 'purchase the pleasure' of violation. However, the result may be different in a system of price discrimination such as day-fines. Under this structure not only the severity of the offense is considered, but also the financial ability of the violator to pay. As a result, the attractiveness of committing an offense is the same for all potential violators.

Although day-fines have the potential to overcome the problems of a fixed-fine, there are factors, which impede its efficient implementation. One such factor is the asymmetric information problem. Data on the financial state of the offender is an essential element for setting the correct fine. Yet, it is private information of the criminal and collection of it by the authorities is costly. Under these circumstances, courts are driven to rely on the declaration of the offender regarding his financial capacity. This article formally demonstrates that due to the fact that increased wealth leads to a higher fine, culprits are always incentivized to underreport their wealth.

In order to increase the flow of correct information between the offender and the enforcement authorities, this article offers to introduce an optimal 'secondary day-fine'. Under this system, prior to sentencing a convicted person to a day-fine for the primary offense, he is required to declare his wealth. With some probability his financial state can be audited. In case he is caught misreporting, the court should impose on him a secondary day-fine in addition to the primary fine. The size of the secondary day-fine depends on several elements: (1) the wealth of the offender (the daily unit), (2) the magnitude of one's misreporting, ${ }^{2}$ and (3) the severity of the primary fine. The wealth-dependency reassures deterrence regardless of the offender's financial state. The magnitude of misreporting achieves marginal deterrence $^{3}$ in addition to the general deterrence. Namely, if not entirely deterring misreporting, the secondary day-fine may at least minimize the gap between the true and the reported wealth. Finally, the third element reassures that offenders are deterred regardless of the severity of the primary fine. Consequently, the 'secondary enforcement' is a fine-discrimination system that may perfectly tailor the punishment to the specific offender, thus increasing the deterrence of underreporting one's wealth.

The topic of day-fines is under-researched in the law and economics literature. To the best of our knowledge, there is only one relevant article that models wealth-dependent fines (Bar Niv and Safra 2002), and another article that analyzes the advantages of day-fines as compared to other models of fine (KantorowiczReznichenko 2015). Therefore, the current article is the first to address the asymmetric information problem arising in the context of day-fines, to formally analyze

\footnotetext{
1 A "fixed fine" is based on the severity of the crime and the blameworthiness of the offender. It does not systematically consider the socio-economic status of the person.

${ }^{2}$ Magnitude of misreporting refers to the ratio between the reported wealth and the true wealth. In other words, it depicts the percentage of the wealth that the offender concealed.

3 The idea of proportional punishment and marginal deterrence is not novel. It was already introduced by Jeremy Bentham in the nineteenth century. However, the term "marginal deterrence" was coined and formally depicted only in a later stage (Stigler 1970; Shavell 1992).
} 
the inefficiencies resulting from it, and to offer a possible solution. It is an important step since the information problem constitutes the reason not to introduce day-fines in certain countries, despite its potential efficiency.

The idea of auditing offenders who received a fine was previously discussed by Polinsky (2006). Nevertheless, his analysis concerns only fixed-fines where the financial information is important ex-post for the enforcement rather than ex-ante for a correct determination of the fine. Furthermore, the model offered by Polinsky significantly differs from the analyzed solution in the current article. ${ }^{4}$

The novelty of the suggested secondary enforcement system is in its structure. It suggests a pecuniary penalty for misreporting that takes several factors into account, thus enabling to tailor the fine to the specific offender. 'Fine-discrimination' system may better deter criminals by raising the costs of misreporting above the private utility gains of each offender. Therefore, the current article offers a policy-relevant solution for increasing the effectiveness of a day-fine system. A wealth-dependent fine might constitute a credible alternative sanction to some imprisonment sentences, thus, increasing its effectiveness has a potential to reduce the high costs of imprisonment. This is especially relevant in the American context where the prison population is the highest in the Western society (Neal and Rick 2016), ${ }^{5}$ and fines are largely underused (Whitman 2009).

The model presented in this article provides a formal way to calculate the optimal relationship between the severity of the primary fine and the severity of the secondary fine, a component that is termed in this article 'the severity factor'. Based on the trade-off between the costs of auditing and the costs of a severer secondary fine, a socially optimal severity factor may be determined and set in the criminal code. Subsequently, the courts may use this severity factor to calculate the optimal secondary fine in each individual case.

The article is structured as follows. Section 2 briefly describes what day-fines are and why they may be more efficient in deterring potential offenders than fixedfines. However, this article treats day-fines as a given system and focuses on the question how to increase its efficiency. ${ }^{6}$ The asymmetric information problem is presented in Sect. 3. In addition, this section demonstrates that with self-reporting system rational offenders would always misreport. Section 4 presents the secondary enforcement system. Finally, some concluding remarks are provided in Sect. 5.

\footnotetext{
4 The main conclusion of Polinsky's model is that (fixed) fines should be lowered in order to induce more offenders to report their income truthfully, and in turn, reduce the auditing costs.

5 For a comparison of the prison population in different countries, see the International Centre for Prison Studies, available at http://www.prisonstudies.org/world-prison-brief (accessed August 3, 2016).

${ }^{6}$ For a comparison of different models of fine and the arguments in favor of day-fine see KantorowiczReznichenko (2018).
} 


\section{Day-fines}

\subsection{What are day-fines?}

A day-fine is a monetary sanction that systematically takes into consideration offender's socio-economic status. Thus, the amount of the fine depends on the gravity of the crime and the financial state of the offender. The day-fine is imposed in two steps. First, based on the gravity of the crime, the court decides on the number of days the offender must pay the fine. In the second stage, after assessing the financial capacity of the culprit, the court imposes the daily unit of the fine. This unit is usually a fraction of the offender's daily income and, in some systems, is pre-set in the law. The total fine, which needs to be paid by the offender, is the multiplication of the number of days by the daily unit. For instance, a particular offender earns $\$ 100$ per day. The daily unit in a certain jurisdiction is $50 \%$ of the daily income. If based on the severity of his offense the judge imposes 10 days of fine, the total fine to be paid by the convicted offender is $100 \times 0.5 \times 10=\$ 500$. On the other hand, if the offender's daily income is $\$ 20$, he would pay for the same crime $20 \times 0.5 \times 10=\$ 100$ Therefore, this type of pecuniary sanction results in an equal relative burden on offenders regardless of their wealth.

A wealth-dependent fine was already suggested in the $19^{\text {th }}$ century by Jeremy Bentham (1931). However, such a fine was adopted in practice only at the beginning of the twentieth century. Finland was the first country to introduce day-fines in 1921 and later on it was followed by other European countries ${ }^{7}$ (for a survey see, Kantorowicz-Reznichenko 2018). At the same period, several South-American countries ${ }^{8}$ also applied this model of fine (Hillsman 1990). In the Unites States, some counties experimented with this punishment during the 1980s-1990s and received positive results regarding the compliance of offenders sentenced to this type of fine (U.S. Department of Justice 1996).

Although the idea behind this fine is similar across jurisdictions, there are different structures of this sanction. For instance, the Finish Criminal Code instructs the court to impose a fine unit equal to approximately $50 \%$ of the offender's daily income ( $\$ 2(2)$, Chapter 2a; Lappi-Seppälä 2009). It restricts the number of days to 120 for one offense, and 240 for two offense ( $\$ 1(1)$, Chapter $2 \mathrm{a} ; \S 3(2)$, Chapter 7). There is no statutory maximal cap on the daily amount of the fine. As a result, the fine might be very high. For instance, in 1999 a $€ 116,000$ (around \$130,000) fine was imposed on a wealthy driver who exceeded the permitted speed limit in Finland. The yearly income of this driver was assessed in millions, thus the daily unit was magnified. ${ }^{9}$ Germany, on the other hand, limits the maximum amount of the daily unit to 30,000 euro. Furthermore, the court may impose up to 360 days of fine ( $\$ 40$ of the German Criminal Code). Due to its special structure, day-fines may be used

\footnotetext{
7 For instance, Sweden (1931), Denmark (1933), Germany (1975), Poland (1997).

8 Peru (1924), Brazil (1969), Costa Rica (1972), Bolivia (1972). Also Cuba introduced day fine in 1936.

9 See "Nokia Boss Gets Record Speeding Fine," BBC News (January 14, 2002) available at http://news. bbc.co.uk/2/hi/europe/1759791.stm (accessed April 17, 2016).
} 
extensively as a criminal sanction. To illustrate, in 2012, around $82 \%$ of all imposed sanctions by the German courts were fines (German Statistics Office 2012). Moreover, this sanction was not merely used to punish minor offenses, but was imposed on offenders committing crimes such as an assault, property crimes, drug offenses, etc. (Albrecht 1991).

\subsection{Wealth-dependent fine}

Fixed-fines are the most common form of pecuniary sanctions. These fines depend on the severity of the offense and the blameworthiness of the offender without systematically taking the offender's wealth into account. A fixed fine has a significant shortcoming. It under-deters wealthy offenders if there is heterogeneity in the wealth levels of potential culprits. To formally reconstruct this argument assume that the offender has the following utility function:

$$
U(H, w)=H+v(w)
$$

In this function $H$ is the utility that the offender receives from committing the crime and $v(w)$ is the utility he receives from his wealth. Every potential offender has his initial wealth and the utility he derives from it. The additional utility from crime is the incentive underlying the choice to commit a crime. Including the sum of these components in the utility function helps to analyze the incentives of the potential offender to commit a crime. It also allows for the analysis of enforcement tools which can deter crime. Moreover, it is assumed that the marginal utility from wealth is always positive $\frac{d v}{d w}>0$ but diminishing $\frac{d^{2} v}{d^{2} w}<0$ since presumably each additional unit of wealth satisfies a less crucial need. ${ }^{10}$ Committing the offense will increase the offender's utility by $H$ but with probability $p$ he will be convicted for the offense and a fine $f$ would be imposed on him. Accordingly, an offender commits offenses if the expected utility from this action is higher than the utility he receives only from his initial wealth (without committing the offense):

$$
H+p \times v(w-f)+(1-p) \times v(w)>v(w)
$$

Given this condition an offender will be deterred from committing the crime if the imminent utility loss through the fine (expected costs of crime) is larger than the utility he gains from committing the crime:

$$
\frac{H}{p} \leq v(w)-v(w-f)
$$

\footnotetext{
10 This implies risk averse individuals. The common assumption is that most people are risk averse. Even though some offenders can be risk seeking, given the nature of offences that are punishable by day fines (minor offences, see Kantorowicz-Reznichenko and Faure forthcoming), it seems reasonable to assume those offenders are more similar to the general population than to the most extreme examples of offenders. Some support for this assumption can be found in a study which investigated the behaviour of traffic rules violators and found that wealthier people respond less to increases in fines (Bar-Ilan and Sacerdote 2004).
} 
This resembles the classical deterrence model offered by Becker (1968). According to this model, crime goes down if the probability of conviction or the fine is increased. On the other hand, crime goes up, if the utility from committing the crime rises. The enforcement authorities are able to change the expected costs of crime by altering the severity of punishment or the probability of being detected and punished. $^{11}$

However, the decision whether to commit the crime is sensitive to the wealth of the offender (Bar Niv and Safra 2002). To analyze this assume that the enforcement authorities set the probability and the level of fine such that the median offender $w_{m}$ is optimally deterred.

$$
\frac{H}{p}=v\left(w_{m}\right)-v\left(w_{m}-f\right) .
$$

Further assume that there exists a wealthy offender that is richer than the median offender $w_{w}>w_{m}$. If the fine is non-zero and given the positive marginal utility assumption, his expected utility loss from committing the offense is lower than the expected loss of the median offender.

$$
v\left(w_{w}\right)-v\left(w_{w}-f\right)<v\left(w_{m}\right)-v\left(w_{m}-f\right)
$$

Therefore, the condition for not committing an offense does not hold for the wealthy offender and hence he will not be sufficiently deterred. Accordingly, it can be concluded that a wealth-dependent fine is socially more desirable if there exists heterogeneity in the wealth levels of potential offenders. However, a question arises how to implement such a policy efficiently.

\subsection{Day-fines as wealth-dependent fines}

A day-fine is an example of a wealth-dependent fine. As explained in Sect. 2.1, it consists of two components in order to calibrate the fine for the gravity of the crime and the offender's wealth.

$$
f(s, w)=n(s) \times d(w)
$$

where $n(s)$ is the number of days that depends on the severity of the crime, and $d$ is the daily unit that depends on the offender's wealth. The number of the imposed days of a fine remains the same for all offenders committing similar crimes. This article concentrates on a generic initial offense and hence the gravity of the primary offense, and accordingly the number of days, is held constant. ${ }^{12}$ Therefore, the primary fine in the current analysis is only a function of wealth $(f(w))$.

\footnotetext{
11 Another way to reduce crime is by increasing the attractiveness of legal opportunities (Becker 1968).

12 This article focuses on the information asymmetry problem around the offender's wealth, which is introduced in Sect. 3.2. Since the analysis of this is independent of the severity of the initial offense, it is held constant for simplicity.
} 


\section{Setting an efficient day-fine}

Given the findings of the previous section, a wealth-dependent fine function $f(w)$ and $\frac{d f}{d w}>0$, such that $\frac{H}{p}=v(w)-v(w-f(w))$ holds, leads to a sanctioning regime that perfectly deters offenders, regardless of their wealth. However, this result relies on the assumption that the sentencing authority has accurate information about the offender's wealth. Intuitively speaking, the key element in the sanction of day-fines is accurate information regarding the financial state of the offender. To achieve the desired deterrence through the usage of this penalty there should be an appropriate tailoring of the sentence to the crime and the offender. Nevertheless, whereas the gravity of the offense is usually observable, the financial state of the offender is private information. Therefore, the sentencing authority has to rely on a weak signal of the offender's wealth. The following sections examine the problems of limited financial information and its implications on deterrence.

\subsection{Asymmetric information and the information costs}

As in the classical contexts such as consumption (Akerlof 1970), employment (Spence 1973) and insurance (Rothschild and Stiglitz 1976), where asymmetric information between the parties has an effect on transactions, also the system of day fines raises the problem of asymmetric information. Whereas the delinquent possesses full knowledge regarding his income and assets, the authorities may not obtain this information without costs. However, this information is essential for the decision regarding the daily unit of the fine. Without this information, the decision regarding the magnitude of the fine may be based solely on the severity of the crime, and in this case equal the fixed-fine.

Some of the criminal codes in the countries practicing day-fines include the sources of information that may be used by the courts to assess the financial state of the offender. For instance, in Finland the courts ought to use the most recent tax report (\$2(3), Chapter 2a, The Criminal Code of Finland). In Switzerland and Denmark, the penal code provides a general obligation for relevant authorities to make available the necessary information for the courts (Article 34(3), The Swiss Criminal Code; $\S 51(4)$, The Penal Code of Denmark).

Whatever the case may be it seems that the costs of gathering this information are non-negligible. In order to properly obtain the needed elements for the daily unit of fine, the courts (or other authorities) need to collect information on the income of the offender, his assets, savings, and expenses that might be deducted from the daily unit. Those are different elements of the criminal's financial state and usually require the assistance of variety of authorities. Thus, the collection of this information regarding a high number of convicted persons is a time consuming and costly endeavor. As stated by two commentators in the American context: "nothing is 
"simple" in assessing an individual's "ability to pay." Relying on legislative, judicial, or administrative efforts to determine an individual's financial status or capacity is fraught with complications. To gain an accurate picture of the income position of an individual, whose work record is irregular at best, is constantly changing, and has financial obligations that might extend across multiple institutional arenas (child support, restitution, court, and state obligations in addition to informal or formal loans taken from family and friends) only can be beset by inaccuracies." (Katzenstein and Nagrech 2011, p. 564).

This problem was explicitly raised in different countries. For instance, in the Spanish criminal justice system day-fines were welcomed, yet perceived as inefficiently used. There was a sense that the investigation of the financial capacity of the offender becomes more costly than the investigation of the crime itself. As a result, courts used intuition to set the daily unit of fine, which led to fines closer to the minimum boundary (Bachmaier and del Moral García 2010). Moreover, the Netherlands has discussed the possibility to adopt the day-fine system, yet rejected this proposal partially due to high expected costs of identifying and gathering the necessary information. One of the main arguments was that this system is too complicated. Calculating the financial capacity of offenders would turn the enforcement authorities to tax services and draw the attention from examining the relevant factors to the crime (Simonis 2001).

Consequently, authorities might view it more efficient to transfer the information costs to the offender, who is the 'cheapest' information provider. One example is Germany, which uses day-fines as the main sanction. Due to the substantial number of criminals who need to be processed by the criminal justice system, the offenders' financial information, which is provided by the police and the public prosecutor, is limited. Most frequently, the information regarding the offender's personal and socio-economic circumstances is gathered through a questionnaire filled by the delinquent himself. As a result, the offender is the primary source of information regarding his income. Since this is the most vital information for the second step of day-fines, German judges developed relatively uniform estimation of income based on the profession of the offender (Albrecht 1991). The reliance on the offender as the source of information regarding his financial state is not practiced only in Germany, but in other jurisdictions as well (Hillsman 1990).

Nevertheless, the usage of an average estimation of income for all offenders in the same profession impedes the advantage of day-fines, i.e. tailoring the fine exactly to the offender and the offense. Not all people in the same profession earn an equal income. The earnings of a person may increase or decrease depending on different factors, e.g. extra working hours, excessive illness days. It is safe to assume that in the case where the offender earns less than the average income in his profession, he would invest in convincing the court to reduce his fine. However, by the same token it is expected that rational offenders would not correct the court if their true income were higher than the average in their profession. In these circumstances there is under-deterrence of offenders who have higher than the average income.

Another striking example for the information problem with respect to day-fines can be found in Sweden. This country has one of the most extensive accesses to individual financial information. In fact, individual tax returns are available online (The Economist 2016). In theory, this should allow courts to gather this information 
and set the most accurate daily unit (Thornstedt 1975). Nevertheless, in practice it is not done (Greene 1992), and a possible explanation might be the high costs of gathering information on each offender that is subject to a day-fine. The Swedish prosecutorial guidelines state explicitly that the main source of information should be the offender. An investigation of the truthfulness of the provided information ought to be conducted only in case there is a suspicion that the information is wrong or incomplete to the extent it can affect the daily unit (Section 1.2 of the Prosecutor General's Guidelines 2007). Recently, a motion was filed to the Swedish parliament requesting to abolish day-fines altogether. One of the main justifications for the motion was a concern that the financial information of the offender is rarely verified. Therefore, it is expected that many offenders underreport and the punishment is under-deterring (Boriana Aberg, Motion to the Swedish Parliament 2014).

\subsection{Incentives to misreport}

Day-fines aim at individualizing the criminal sentencing with respect to wealth. This kind of a system allows imposing on the offender the appropriate burden of fine, which would constitute sufficient expected costs of crime, yet at the same time enable the offender to 'serve' his punishment. To set the appropriate fine there is a need to be informed of the actual wealth of the offender. Since the costs of gathering information are high, as described in the previous section, the courts might want to rely on the offender's declaration of income. Nonetheless, in the absence of expected costs for misrepresenting, based on the deterrence theory, rational offenders would always underreport their wealth. Forasmuch as the severity of a fine is positively correlated with the person's wealth, there is a strong incentive to report an income below the true earnings of the offender.

In other words, the offender has no incentive to report his true wealth. For illustration, take the utility function of the offender, and assume that he has been convicted for the primary crime. The fine for the offense for which he was convicted depends on the wealth he reports $\tilde{w}$. Therefore, the offender faces the following decision problem:

$$
\max _{\tilde{w}}(H+v(w-f(\tilde{w}))
$$

If there are no constrains imposed on his decision and given that the fine increases with wealth, the offender chooses to report zero wealth $(\tilde{w}=0)$ in order to maximize his utility. ${ }^{13}$ This means that the offender receives a fine that is lower than the one he would receive if he would report truthfully. Consequently, the expected costs of committing an offense are lower as well. Taking this result and plugging it into the offender's initial choice problem-whether to commit an offense or not-confirms the intuition that unconstrained self-reporting impedes deterrence.

$$
\frac{H}{p}=v(w)-v(w-f(w))>v(w)-v(w-f(\tilde{w}=0))
$$

\footnotetext{
13 One obvious constrain is of course, not reporting a negative income.
} 
This impediment to deterrence arises since the expected costs of committing an offense are too low and hence the 'no-offense' condition does not hold. Some anecdotal evidence for such behavior can be found in the American experiments with day-fines (Vera Institute of Justice 1995). Consequently, the self-reporting of wealth requires an appropriate constraining mechanism in order to ensure the effective deterrence of the primary fine regime.

\subsection{Self-reported financial information in the tax-collection system}

Reliance on self-reported wealth may be found in the context of tax enforcement. ${ }^{14}$ Since annually auditing the entire working population is costly, many countries adopt the model of tax reporting. Under this system individuals are required to report to the tax authorities the sources of their income and their amounts. ${ }^{15}$ In order to induce compliance with this requirement, those systems introduced costs for misreporting. Namely, with certain probability individuals may be audited, and if found underreporting, might be punished.

In the U.S., for instance, the main source of financial information on which the Internal Revenue Service (IRS) relies is the self-assessments of individuals' income. This procedure is named 'voluntary compliance'. If individuals (or corporations) decide to misreport their wealth in order to evade paying taxes, they might be subject to civil audit or criminal investigation. In case they are caught, a sentence may be imposed on them, including the severe punishment of imprisonment. Furthermore, in order to increase the deterrent effect of this system, information regarding convictions is publicized. ${ }^{16}$

The choice whether to misreport income for the purpose of tax evasion was modelled in the framework of economics of crime already in the 1970s (Allingham and Sandmo 1972). In the simplified model the individual has a choice whether to report his income correctly or to misreport it. With certain probability the individual will be audited, and if caught misreporting, would be required to pay a tax on the concealed income and an additional penalty for misreporting. This model demonstrates, among others, that increasing the sanction or the probability for misreporting one's wealth will result in the increase of the reported wealth.

The systems of tax collection and setting an efficient day-fine have similar characteristics in some respects. Under both systems, the amount an individual is required to pay positively correlates with his income. Consequently, there are similar incentives to underreport the wealth. Therefore, some lesson may be learned from the structure of the tax enforcement system. The remaining of this article develops a model of the secondary enforcement system that introduces incentives for true reporting of wealth.

\footnotetext{
14 For an analysis of methods to induce self-reporting of general criminal behavior see, Innes (2000).

15 For instance, this is practiced in the U.S., The Netherlands.

16 Internal Revenue Service, Criminal Investigation (CI) At-a-Glance (2014), available at http://www. irs.gov/uac/Criminal-Investigation-(CI)-At-a-Glance (accessed January 15, 2016).
} 


\section{Possible solution: the "secondary enforcement system"}

As demonstrated in the previous sections, complete information regarding the wealth of the offender is the key element to the imposition of an efficient day-fine. Yet, collecting this information can be a costly task for the law enforcement authorities. Conversely, an offender's costs of providing information about his wealth may be assumed to be very low, given that this is his private information. Thus, transferring these costs to the convicted culprit rather than imposing them on the state is a cost-effective policy. Nevertheless, the offender needs to be adequately incentivized to provide his private information. One method to set such incentives, as done also in the context of tax enforcement, is to introduce (expected) costs of misreporting. These costs may be introduced through the criminal punishment of misreporting. To this end, the current article proposes to establish a "secondary enforcement system" which imposes an independent day-fine for misreporting the financial information.

\subsection{The secondary sanction}

The suggested secondary enforcement system becomes relevant after the offender is convicted for the primary offense. At this point the sentencing authority requires the offender to provide precise information about his wealth in order to determine the amount of the primary fine $f_{1}(\tilde{w})$. To incentivize the offender not to misreport, the criminal justice system treats misreporting as a secondary offense that is punishable by an additional fine. In order to identify misreporting, the offender's wealth is audited with the probability $0<p_{2}<1$ and if misreporting is determined, a secondary fine $f_{2}$ is imposed.

This secondary fine for misreporting may be implemented either as a fixed-fine or as an extended day-fine. A fixed secondary fine would punish all misreporting offenders the same, not taking into account their wealth or the magnitude of their misreporting. ${ }^{17}$ Such a fine constrains effective deterrence. First, it under-deters rich offenders due to wealth independency. Second, it does not achieve marginal deterrence since the fine is not adjusted to the gravity of misreporting.

Therefore, in order to achieve an optimal deterrence, this article offers to impose a secondary day-fine. This fine would take the following elements into account. First, through the daily unit, the fine would capture the wealth of the offender, hence deterring equally high and low-income offenders. Second, by varying the fine based on the magnitude of misreporting, this sanction would achieve marginal deterrence. Namely, if misreporting behavior would not be entirely deterred, convicted offenders would at least be incentivized to report a closer wealth to the true one. Finally, an

\footnotetext{
17 An example of a general fine for misreporting which does not take into account the magnitude of the deception may be found in Sect. 6, Chapter 16 of the Criminal Code of Finland: "A person who in order to obtain economic benefit provides a public authority, for the purpose of imposing a fine, essentially false or misleading information on his or her income, maintenance liability or other circumstance affecting his or her solvency, shall be sentenced for fine deception to a fine or to imprisonment for at most three months."
} 
extension of the day-fine may be found in the third element. Namely, the secondary day-fine would also depend on the severity of the primary fine. This structure would assure optimal deterrence of offenders regardless the severity of their primary fine. ${ }^{18}$

Consequently, a suitable measure for the gravity of the secondary offense would account for the magnitude of misreporting (in relation to the total wealth) and the severity of the primary fine. Formally speaking the percentage of the total wealth that was not reported is multiplied by the number of days that were imposed under the primary fine $\frac{w-\tilde{w}}{w} \times n_{1}$. As a result of this composition, the secondary fine positively depends on the gravity of misreporting and hence the offender faces the following utility maximization problem when forming his reporting decision.

$$
\max _{\tilde{w}}\left[\left(1-p_{2}\right) v\left(w-f_{1}(\tilde{w})\right)+p_{2} v\left(w-f_{1}(w)-f_{2}(w, \tilde{w})\right)\right]
$$

Under this twofold fine structure the convicted offender is confronted with a trade-off between a higher primary and a higher secondary fine. If he decides to report his true wealth, the primary fine is higher but the potential secondary fine is zero. Conversely, if the offender underreports his wealth, he decreases the primary fine but risks a secondary fine, in case his wealth is audited. Because both fines depend on the magnitude of his misreporting, a utility maximizing offender chooses to report the level of wealth for which the sum of the utility loss is minimal.

The last stage is to determine the relation between the primary and the secondary fine. The primary fine is a regular day-fine, which consist of the number of days $n$ and the daily unit $d(w)$. The daily unit is obtained by taking a fraction of the offender's wealth $d(w)=\alpha \times w$. This fraction is fixed in the law in some jurisdictions. Therefore, the primary fine function based on the offender's reported wealth is composed as:

$$
f_{1}(\tilde{w})=n \alpha \tilde{w}
$$

The secondary fine is also implemented as a day-fine that consist of a number of days and a daily unit $f_{2}=n_{2} \times d(w)$. The number of days for the secondary fine is determined by the percentage of misreporting multiplied by the number of days of the primary fine and the severity factor, $n_{2}(w, \tilde{w})=\frac{w-\tilde{w}}{w} \times n_{1} \times \beta$. The severity factor

\footnotetext{
18 The following hypothetical example illustrates the need for the correlation between the secondary and the primary fine. Offender A was convicted for an aggravated assault, while offender B was convicted for minor theft. Both offenders have the same wealth, which is measured as $\$ 100$ per day. The daily unit is set in the law as $50 \%$ of the offender's daily wealth. Offender A receives 50 days of fine, and offender B receives 10 days. Both offenders report $90 \%$ of their true wealth. In other words, they state to the court that their daily wealth amounts to $\$ 90$. Consequently, the fine imposed on offender $\mathrm{A}$ is $90 \times 0.5 \times 50=\$ 2250$. While offender B is sentenced to a fine of $90 \times 0.5 \times 10=\$ 450$. Therefore, offender A's benefit from misreporting is $\$ 250$, and offender B's gain is $\$ 50$. Following their self-reporting, both offenders are audited and their under-reporting is discovered. If the maximum secondary fine, which is set in the law, is fixed and does not depend on the severity of the primary fine, those two offenders may face different incentives. For instance, if the maximum secondary fine is $\$ 200$, it would deter offender B since his expected gain from misreporting with regard to the primary offense is only $\$ 50$. On the contrary, offender A gains $\$ 250$ from misreporting, thus it is still rational for him to under-report his wealth if the expected punishment for it is only $\$ 200$.
} 
$(\beta)$ states by how much the number of the secondary days of fine is larger than the days of the primary fine. Thus, it constitutes the severity of the secondary enforcement system and should be set ex-ante in the law in order to deter misreporting. The daily unit remains the same for both fines but is of course corrected according to the true wealth after the audit was performed. Therefore, the function for the secondary fine is denoted as:

$$
f_{2}(w, \tilde{w})= \begin{cases}n \alpha \beta(w-\tilde{w}), & \tilde{w}<w \\ 0, & \tilde{w} \geq w\end{cases}
$$

Given these two fine functions the maximization problem for the reported wealth choice changes to:

$$
\max _{\tilde{w}}\left(1-p_{2}\right) v(w-n \alpha \tilde{w})+p_{2} v(w-n \alpha w-n \alpha \beta(w-\tilde{w}))
$$

Following up on the previous assumption that the offender cannot report a negative wealth and given the assumed fine functions, it follows that the offender's reporting choice lies in the interval $[0, w] .{ }^{19} \mathrm{~A}$ utility maximizing offender will chose $\tilde{w}$ such that this utility is optimal. The specific choice of $\tilde{w}$ is given by the optimality condition, which is the solution to the offender's maximization problem.

$$
\beta=\frac{1-p_{2}}{p_{2}} \frac{v^{\prime}(w-n \alpha \tilde{w})}{v^{\prime}(w-n \alpha w-n \alpha \beta(w-\tilde{w}))}
$$

While seeking to determine the exact value of $\tilde{w}$ is not desirable, it seems worthwhile to better understand how the parameters of the enforcement system influence the offender's reporting choice and what happens to it if they are altered. Figure 1 illustrates how the offender's reporting choice changes depending on the severity of the secondary enforcement system (represented by the severity factor) for a given probability of an audit. If the severity factor increases then the offender chooses to report a higher level of wealth. This behavior pattern evolves because with his reporting choice the offender has to trade off actual utility loss from the primary fine with the expected utility loss from a secondary fine. A higher severity factor implies a severer secondary fine and hence the expected utility loss through the secondary enforcement increases. If the expected utility loss increases, misreporting becomes more costly and hence the offender reacts by reporting a higher wealth in order to avoid these potential utility losses. This positive correlation between the severity factor and the reported wealth persists until $\beta^{+}$. At this point the secondary enforcement system is sufficiently deterring misreporting behavior.

Figure 2 shows how the offender's reporting-choice changes depending on the probability of an audit of his actual wealth, given a constant severity factor. If the

\footnotetext{
19 Obviously, the offender will not chose to report more than his actual wealth $\tilde{w}>w$. This is because $\tilde{w} \geq w$ implies that there is no secondary fine $f_{2}=0$ and hence $v(w-\alpha \tilde{w})$. Given this $v(w-\alpha w)>v(w-\alpha \tilde{w})$ for $\forall \tilde{w}>w$ holds which implies that reporting the true wealth strictly dominates all reporting choices above this level.
} 
probability of an audit is very low, the expected secondary fine is low, which implies that underreporting only causes a low expected utility loss. Hence, the offender chooses to report zero wealth since thereby he avoids an actual loss of utility by the primary fine. As the probability of an audit increases, the offender's reported wealth also increases. Since an increase in the probability of an audit simultaneously increases the expected utility loss from the secondary fine, the offender rebalances the two utility losses. This process continues until the point $p^{+}$at which the offender chooses to report his true wealth because the expected utility losses by the secondary fine fully outweigh any utility gains from underreporting.

In order to determine the severity factor, which fully deters underreporting, the reported wealth is set to the true $(\tilde{w}=w)$ and then plugged into the optimality condition, which simplifies to:

$$
\beta^{+} \geq \frac{1-p_{2}}{p_{2}}
$$

This term implies that in order to achieve perfect deterrence of underreporting, the severity factor should be equal to the reciprocal of the audit probability, which is normalized to zero. This relationship is illustrated in Fig. 3, which shows that for audit probabilities below $25 \%$ the secondary fine has to be exceedingly severe. This requirement becomes more lenient as the probability increases. At an audit probability of $100 \%$ no secondary fine is necessary anymore. This result reflects the offender's trade-off between the utility loss by the primary fine and the expected utility loss by the secondary fine. Given this relation for full deterrence, it can be inferred that the offender always chooses to report his true wealth if:

$$
\beta \geq \frac{1-p_{2}}{p_{2}} \Leftrightarrow p_{2} \geq \frac{1}{1+\beta}
$$

In conclusion, to prevent underreporting, the severity of the secondary fine must account for the probability of an audit in an appropriate manner. Due to the high costs of gathering the financial information of the offender, as explained in Sect. 3.1, wealth audits in practice can only be performed with a low probability. Consequently, the severity factor has to be sufficiently high in order to deter misreporting. This leads to severity of the secondary fine that compensates for the low audit probability in practice.

\subsection{Legal limitations for the severity factor}

The results of the previous section indicate that for every positive audit probability there exists a severity factor such that the secondary enforcement system is fully deterring. Therefore, in theory even a low probability of auditing can be fully deterring, if the severity factor is set sufficiently high. Here we use the standard assumption that increasing the size of the fine, unlike increasing probability, is costless. In the context of day fines, increasing the number of the imposed days of fine for misreporting is assumed to be costless. However, in all criminal justice systems that apply day-fines the maximum 
Fig. 1 Offender's reporting choice as a function of the severity factor given a constant probability of an audit

Fig. 2 Offender's reporting choice as a function of the probability of an audit given a constant severity factor
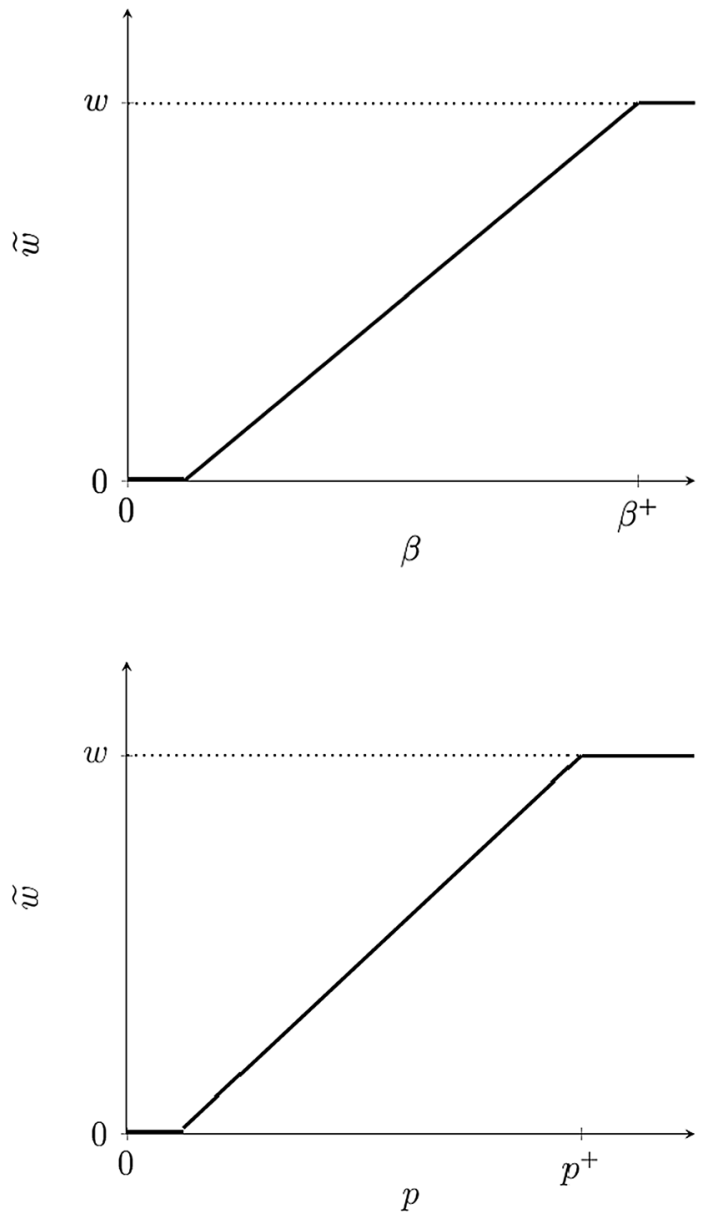

number of days that can be imposed on the offender are limited by the criminal code. In some jurisdictions the maximum number of days can be doubled (e.g. $\S 1(1)$, Chapter $2 \mathrm{a}$ and $\S 3(2)$, Chapter 7 of The Criminal Code of Finland; Sections 40(1) and 54(4) of The German Criminal Code) for multiple offenses. Nevertheless, there is always a statutory limit of the maximum number of days that can be imposed within a day-fine sentence. ${ }^{20}$ In the context of the secondary enforcement system this limitation on the maximum number of days implies that the sum of the number of days from the primary fine and the secondary fine must be below this legal cap $N_{\max } \geq n_{1}+n_{2}$. As presented

\footnotetext{
${ }^{20}$ The reason for this practice might be to avoid "inhumane or degrading treatment or punishment." See for example, Article 3 to the European Convention on Human Rights, and its analysis in the context of life imprisonment (European Court of Human Rights, Press Unit, October 2015). Not limiting the number of day-fines might turn this punishment to a financial life servitude. This is especially unreasonable since, unlike with life imprisonment, the most severe crimes are not dealt with fines.
} 
Fig. 3 The fully deterring $\beta$ as a function of $\mathrm{p}$

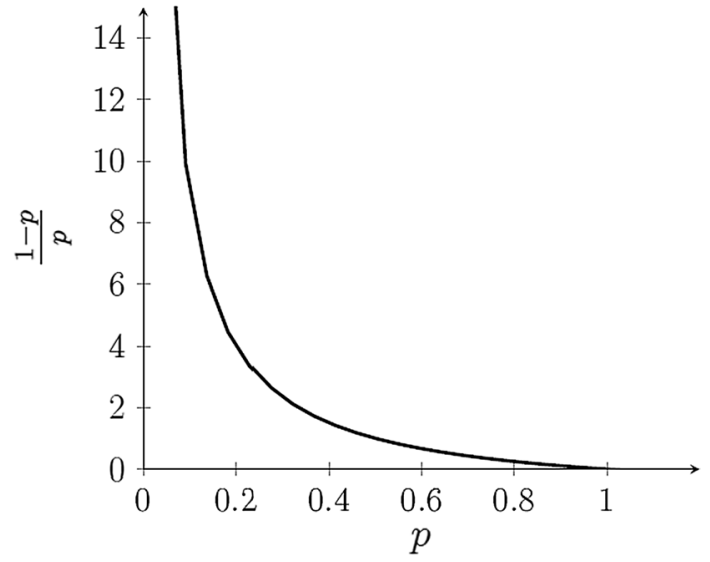

in the previous sections, the secondary fine is determined by the multiplication of the severity factor by the number of days of the primary fine $N_{\max } \geq n_{1}+n_{1} \times \beta$. This means that, for the existing statutory limit on maximum number of days and a given severity factor there exists a threshold point $n_{z}$ for which the sum of days from the primary and the secondary fine is equal to the statutory limit $N_{\max }=n_{z} \times(1+\beta)$. This threshold point, therefore, denotes the maximum number of primary-fine-days until which the secondary enforcement system is fully deterrent:

$$
n_{z}=\frac{N_{\max }}{1+\beta}
$$

Figure 4 illustrates this relationship. Consider points $n_{a}$ and $n_{b}$, which are bellow or above the threshold point $\left(n_{z}\right)$ respectively. If the number of the primaryfine-days $\left(n_{a}\right)$ is below the threshold point the addition of the secondary-fine-days does not exceed the statutory limit. Thus, the secondary enforcement system is fully deterrent. On the other hand, if the number of the primary-fine-days $\left(n_{b}\right)$ is above the threshold point, the secondary fine cannot be fully imposed because the addition of the secondary-fine-days would exceed the statutory limit.

In order to remain within the lawful boundaries the number of days of the secondary fine must be reduced. Adjusting the number of days of the secondary fine implies that the actual (effective) severity factor will be below the nominal severity factor, which is the factor that is set in the law in order to fully deter misreporting. Therefore, it can be concluded that the actual severity factor depends on the number of days of the primary fine:

$$
\beta_{z}\left(n_{1}\right)\left\{\begin{array}{l}
=\beta \text { if } n_{1}<n_{z} \\
<\beta \text { if } n_{1} \geq n_{z}
\end{array}\right.
$$




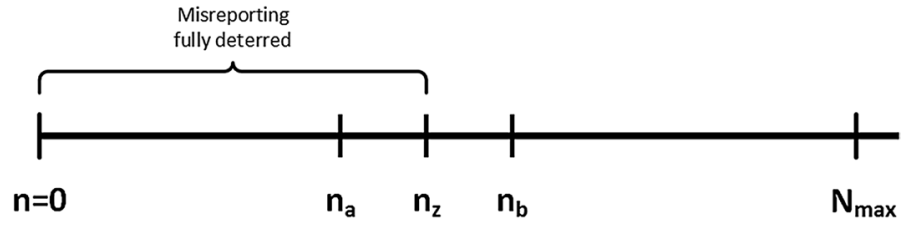

Fig. 4 a caption of the line that indicates the threshold point

Consequently, the higher the number of days of the primary fine is, the less days are 'available' for the secondary fine. Increasing the number of days for the primary fine above the threshold point (if $n_{1} \geq n_{z}$ ), leads accordingly to a decrease of the actual severity factor $\frac{d \beta_{z}}{d n_{1}}<0$.

A decrease of the actual severity factor below the fully deterring, nominal severity factor leads to underreporting (see Sect. 4.1). Figure 5 illustrates the underreporting problem for an actual severity factor $\beta_{z}$ that is below the fully deterring level $\beta^{+}$. An actual severity factor of $\beta_{z}$ will, therefore, cause the offender to underreport his wealth at level $w_{z}$. Generalized, this means that the larger the difference between the nominal and the actual severity factor is, the more will the offender underreport his wealth $\frac{d \tilde{w}}{d \beta^{+}-\beta_{z}}<0$.

Underreporting reduces the primary fine, which in turn leads to under-deterrence of the primary offenses. Under-deterring the primary offenses increases the overall level of crime, which poses costs on the society. An indication of these costs is given by function (18), which denotes the extent of forgone deterrence. ${ }^{21}$ To capture the forgone deterrence the function takes the fraction of wealth that is misreported multiplied by the primary number of days. ${ }^{22}$

$$
C_{n}(n)=\frac{w-\tilde{w}(n)}{w} \times n
$$

In order to get the extent of the total costs we need to aggregate the individual costs of misreporting. For the aggregation, a distribution function $D(n)$ that describes the frequency of each specific number of primary day-fine in our legal system is required. Multiplying $D(n)$ with $C_{n}(n)$ gives, hence, the extent of the underreporting problem for a given primary fine. The extent of total costs is obtained by taking the integral over the range of primary-fine-days from the threshold point to the statutory limit on days.

\footnotetext{
${ }^{21}$ These costs include different burdens imposed by crimes, and it also include the forgone revenues due to lower fines. Naturally, it does not provide directly the exact costs to society. A measure of such costs requires an empirical investigation of the welfare costs of forgone deterrence.

${ }^{22}$ The element of number of days in day-fines, i.e. $n$, reflects the severity of the crime. In theory this can serve as a proxy for the costs the crime imposes on the society. Therefore, if we connect the extent of misreporting to the number of days, we could say it reflects the changes in the costs imposed on the society.
} 
Fig. 5 A caption of the relation between the actual severity factor and the reported wealth

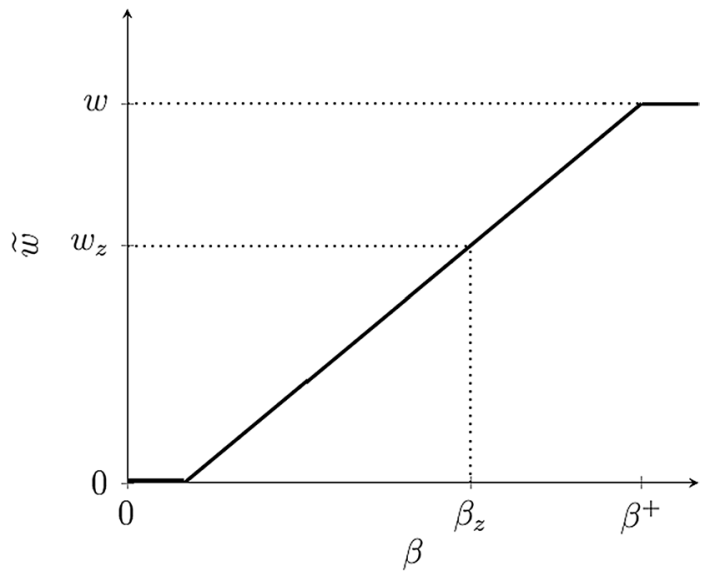

$C_{\beta}(\beta)=\int_{n=\frac{N_{\max }}{1+\beta}}^{N_{\max }} D(n) \times C_{n}(n)$

$C_{\beta}(\beta)$ states the costs of a certain severity factor in terms of underreporting. The function depends on the severity factor because it determines the threshold point, which denotes the lower boundary of the integral. For instance, if the severity factor $\beta$ increases, the threshold point $\frac{N_{\max }}{1+\beta}$ shifts down. This in turn, increases the range of the integral. Therefore, the extent of the total costs goes up. Since both D and C are always positive, it can be concluded that the costs are increasing in the severity factor $\frac{d C_{\beta}}{d \beta}>0$.

\subsection{The optimal combination between the severity factor and the audit probability}

As explained in the previous section, an increase in the severity factor might increase the social costs (hereinafter: 'the costs of the severity factor'). The audit costs of the secondary enforcement system, on the other hand, are the costs of one audit multiplied by the total number of audits (see Sect. 3.1). Increasing the audit probability is costly forasmuch as it factually means that more audits have to be conducted by the law enforcement authorities. This suggests that different types of financial information, such as income, assets, obligations, number of dependents, must be collected from different authorities. Since each wealth-audit is a separate task and they are independent from each other, no economies of scale can be realized while increasing the audit-probability. Having a larger audit department can increase the speed of auditing but not its costs given the additional recourses spent on a larger staff. As a result, it is assumed that the cost function for the audit probability is linear and that the total costs increase by $\gamma$ for each percentage point increase. 


$$
C_{p}(p)=\gamma \times p
$$

As discussed in Sect. 4.1, deterrence can be improved both by increasing the audit probability as well as by increasing the severity factor. Because of these two options, there exists an infinite set combinations of audit probability and severity factor, which induces the offenders to truthfully report their wealth. To judge which of these combinations is the most socially desirable, both costs of the secondary enforcement system have to be taken into account. The optimal combination minimizes the sum of the audit costs and the social costs of the severity factor. Since both elements of the secondary enforcement system entail costs, an optimal combination of a severity factor and a probability of audit can be found by a constrained optimization of the total secondary enforcement costs.

$$
C(p, \beta)=C_{p}(p)+C_{\beta}(\beta)
$$

Therefore, the optimization problem can be defined as minimizing the total social costs while ensuring deterrence of misreporting. The constraint for this minimization problem is Eq. (14), which specifies all fully-deterring combinations of audit probability and severity factor. The first derivative of this function shows that the severity factor is decreasing in the audit probability $\frac{d \beta}{d p}<0$, which means, accordingly, that the severity factor's contribution to the enforcement costs is decreasing in the probability of an audit $\frac{d C_{\beta}}{d \beta}<0$. In other words, the higher the probability of an audit is the lower are enforcement costs that are generated by the severity factor. This interdependency is intuitive, since the severity factor and the audit probability are substitutes and hence an increase in one allows a decrease of the other without conflicting the full deterrence constraint. Rewriting the severity factor's costs as a function of the audit probability and plugging in the explicit audit costs function leads to the following secondary enforcement costs function:

$$
C(p)=\gamma \times p+C_{\beta}(p)
$$

To find the optimal combination of severity factor and probabilities of audit, the first derivate of the modified enforcement costs function is taken. Equalizing the first derivate and solving for the probability of an audit leads the following condition for minimal secondary enforcement costs.

$$
-\frac{d C_{\beta}}{d p}=\gamma
$$

This equation shows the trade-off between auditing costs and the social costs of forgone deterrence. Reducing the probability of an audit, and thereby the auditing costs, requires an increase of the severity factor. Increasing the severity factor imposes some social costs since not all primary offenses can be deterred with the secondary enforcement system. However, decreasing the audit probability from $100 \%$ requires only a small increase in the severity factor, and thereby a small increase of the social costs of forgone deterrence. This means that at a point of certain auditing probability the marginal cost of auditing are significantly higher than 
the marginal social cost of the severity factor. The difference in the marginal cost declines with every reduction of the auditing probability. Nevertheless, as long as marginal costs of auditing are higher that the marginal costs of the severity factor, reducing the probability is socially desirable. This is true until the point where the two marginal costs are equal, which is the optimal level of auditing. Equation (23) specifies this socially optimal combination of the audit probability and the severity factor for the secondary enforcement system.

This combination between audit probability and the size of the severity factor 'sacrifices' a certain level of deterrence. However, this is defensible in terms of social welfare costs. In a system with scarce resources, not all crimes can be deterred. Therefore, as already presented by Becker (1968), policy-makers need to choose the level of enforcement that minimizes the total costs of crime to society. In the specific case of day-fines, the high costs of auditing justify a certain level of forgone deterrence.

\section{Concluding remarks}

This article is the first to formally analyze possible impediments to an efficient use of the day-fine system. Day-fines have a potential to extend the use of pecuniary sanctions and to reduce the number of fine-defaulters. This fine considers not only the severity of the sanction, but also the financial state of the offender. Hence, it imposes an equal relative burden of punishment on all offenders committing similar crimes, regardless of their wealth. Nevertheless, this system faces significant obstacles to efficiency. One of these hurdles is the cost of collecting the required financial information. The data on the wealth of the offender is essential to set the proper fine. However, the offender, who has no incentives to reveal it, possesses this information. The enforcement authorities are able in theory to acquire this information, yet in a costly manner.

The novelty of this article is in offering a secondary day-fine, which depends on multiple factors, in order to induce truthful self-reporting of one's wealth. This secondary fine considers the wealth of the offender, the level of his misreporting and the gravity of the primary fine. Such system allows for the tailoring of the fine to each particular case, thus increasing individual and general deterrence. Furthermore, a model developed in this article enables to determine an optimal severity factor that minimizes the social costs of the secondary enforcement system.

To date, half of the EU member states and a few American States apply the model of day-fines. Therefore, the suggested secondary enforcement system has a high societal relevance. Furthermore, it can be expected that solving the asymmetric information problem and decreasing the costs of information would attract more jurisdictions to apply this fine.

Acknowledgements We would like to thank Christoph Engel, Libor Dusek, Heico Kerkmeester, Oren Gazal, Jaroslaw Kantorowicz; conference participants at the 32nd Annual Conference of the European Association of Law and Economics (EALE); workshop participants at the EMLE MTM Law and Economics Workshop (2015); seminar participants at the Max-Planck Institute for Research on Collective 
Goods in Bonn, Germany; and anonymous reviewers for their useful comments. Any errors or omissions are our own.

Open Access This article is licensed under a Creative Commons Attribution 4.0 International License, which permits use, sharing, adaptation, distribution and reproduction in any medium or format, as long as you give appropriate credit to the original author(s) and the source, provide a link to the Creative Commons licence, and indicate if changes were made. The images or other third party material in this article are included in the article's Creative Commons licence, unless indicated otherwise in a credit line to the material. If material is not included in the article's Creative Commons licence and your intended use is not permitted by statutory regulation or exceeds the permitted use, you will need to obtain permission directly from the copyright holder. To view a copy of this licence, visit http://creativecommons.org/licen ses/by/4.0/.

\section{References}

Aberg, B. (November, 2014). Cancel daily fines as punishment. Motion to the Swedish Parliament. Retrieved from June 28, 2015 from http://www.riksdagen.se/sv/Dokument-Lagar/Forslag/Motioner/Avskaffadagsboter-som-straffp_H202451/?text=true. (in Swedish)

Akerlof, G. A. (1970). The market for lemons: Quality uncertainty and the market mechanism. The Quarterly Journal of Economics, 84, 3.

Albrecht, H.-J. (1991). Fines in the criminal justice system. In K. Sessar (Ed.), Developments in crime and crime control research (pp. 150-169). New York: Springer.

Allingham, M. G., \& Sandmo, A. (1972). Income tax evasion: A theoretical analysis. Journal of Public Economics, 1, 323-338.

Bachmaier, D. L., \& del Moral García, A. (2010). Criminal law in Spain. Alphen aan den Rijn: Kluwer Law International.

Bar Niv, M., \& Safra, Z. (2002). On the social desirability of wealth-dependent fine policies. International Review of Law and Economics, 22, 53-59.

Bar-Ilan, A., \& Sacerdote, B. (2004). The response of criminals and noncriminals to fines. The Journal of Law and Economics, 47(1), 1-17.

Becker, G. (1968). Crime and punishment: An economic approach. The Journal of Political Economy, 76, 169-217.

Bentham, J. (1931). Theory of legislation (Vol. 2). New York: Harcourt Brace Co.

European Court of Human Rights. (2015). Factsheet-Life imprisonment. Press Unit (October 2015). Retrieved August 1, 2016 from http://www.echr.coe.int/Documents/FS_Life_sentences_ENG.pdf.

Greene, J. (1992). The Staten Island day-fine experiment. In D. C. McDonald (Ed.), Day fines in American Courts: The Staten Island and Milwaukee experiments (pp. 13-57). Washington, DC: National Institute of Justice.

Hillsman, S. T. (1990). Fines and day fines. Crime and Justice, 12, 49-98.

Innes, R. (2000). Self-reporting in optimal law enforcement when violators have heterogeneous probabilities of apprehension. Journal of Legal Studies, 29, 287-300.

Kantorowicz-Reznichenko, E. (2015). Day-fines: Should the rich pay more? Review of Law and Economics, 11, 481-501.

Kantorowicz-Reznichenko, E. (2018). Day fines: Reviving the idea and reversing the (costly) punitive trend. American Criminal Law Review, 55(2), 333.

Kantorowicz-Reznichenko, E., \& Faure, M. (Eds.), Day fines in Europe: Assessing income-based sanctions in criminal justice systems. Cambridge, Cambridge University Press (forthcoming).

Katzenstein, M. F., \& Nagrech, M. (2011). A new punishment regime. Criminology \& Public Policy, 10, 555-568.

Lappi-Seppälä, T. (2009). Imprisonment and penal policy in Finland. In P. Wahlgren (Ed.), Scandinavian studies in law (Vol. 54). Stockholm Institute for Scandinavian Law: Stockholm.

Leaders. (April 16, 2016). Tax transparency: Two rights, wrong policy. The Economist. Retrieved July 30, 2016 from http://www.economist.com/news/leaders/21696939-push-publish-peoples-tax-returns-pitstransparency-against-privacy-which-should-win-two.

Neal, D., \& Rick, A. (2016). The prison boom and sentencing policy. Journal of Legal Studies, 45, 1-41.

Polinsky, M. (2006). Optimal fines and auditing when wealth is costly to observe. International Review of Law and Economics, 26, 323-335. 
Riksåklagarens Riktlinjer, Beräkningen av dagsbotsbeloppet vid strafföreläggande (May 23, 2007). ["Prosecutor General's Guidelines: The calculation of a day-fine amount in connection with an order of summary punishment". EKR and MK].

Rothschild, M., \& Stiglitz, J. (1976). Equilibrium in competitive insurance markets: An essay on the economics of imperfect information. The Quarterly Journal of Economics, 90(4), 629-649.

Shavell, S. (1992). A note on marginal deterrence. International Review of Law and Economics, 12, 345-355.

Simonis, J. (2001). Is Ons Strafrecht Gebaat bij de Invoering van een Dagboetestelsel. DD 31, 476-494. ("Does Dutch criminal law profit from the introduction of a day fine system").

Spence, M. (1973). Job market signaling. The Quarterly Journal of Economics, 87(3), 355-374.

Stigler, G. J. (1970). The optimum enforcement of laws. Journal of Political Economy, 78, 526-536.

Strafverfolgung - Fachserie 10 Reihe 3 - 2012, Table 3.3 (Statistics of Germany).

Thornstedt, H. (1975). The Day-Fine System in Sweden. Criminal Law Review, 307-312.

U.S. Department of Justice. (1996). How to use structured fines (day fines) as an intermediate sanction. Washington, DC: Vera Institute of Justice.

Vera Institute of Justice. (1995). Structured fines as fair and collectable punishment in American Courts. Washington, DC: Vera Institute of Justice.

Whitman, J. Q. (2009). Equality in criminal law: The two divergent western roads. Journal of Legal Analysis, 1, 119-165.

Publisher's Note Springer Nature remains neutral with regard to jurisdictional claims in published maps and institutional affiliations. 